Check for updates

Cite this: RSC Adv., 2019, 9, 17415

DOI: $10.1039 / c 9 r a 90041 a$

www.rsc.org/advances

\title{
Correction: Surface core-shell magnetic polymer modified graphene oxide-based material for 2,4,6-trichlorophenol removal
}

\author{
Mei-Lan Chen, ${ }^{a}$ Jian-Qing Min, ${ }^{a}$ Sheng-Dong Pan ${ }^{\mathrm{bc}}$ and Mi-Cong Jin*bc
}

Correction for 'Surface core-shell magnetic polymer modified graphene oxide-based material for 2,4,6-trichlorophenol removal' by Mei-Lan Chen et al., RSC Adv., 2014, 4, 63494-63501.

The authors apologise that parts of the data presented in Fig. 1, 2 and 5 are incorrect.

The authors have repeated the experiments to provide replacement data for Fig. 1, 2(a) and 5(b, c). The new figures have been reviewed by an expert and are provided below in order to fulfil the journal's responsibility to correct the scientific record, in accordance with the guidelines provided by the Committee on Publication Ethics (COPE). This correction does not alter the conclusions presented in this RSC Advances paper.

(1) The original version of Fig. 1 had been inappropriately modified using photoshop to make the images more appealing. The authors apologise for this and understand that any type of image manipulation is not acceptable. The corrected version of Fig. 1 is shown here:

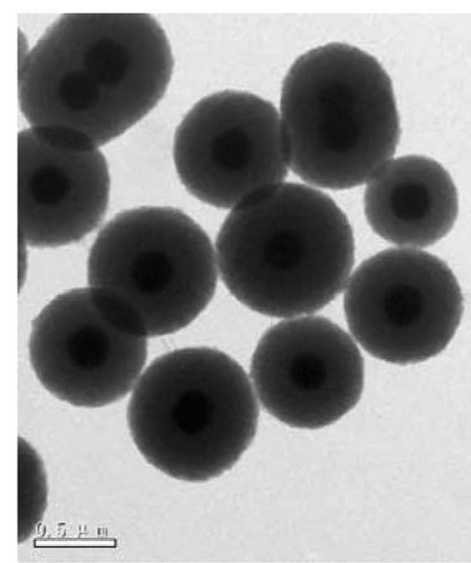

(a)

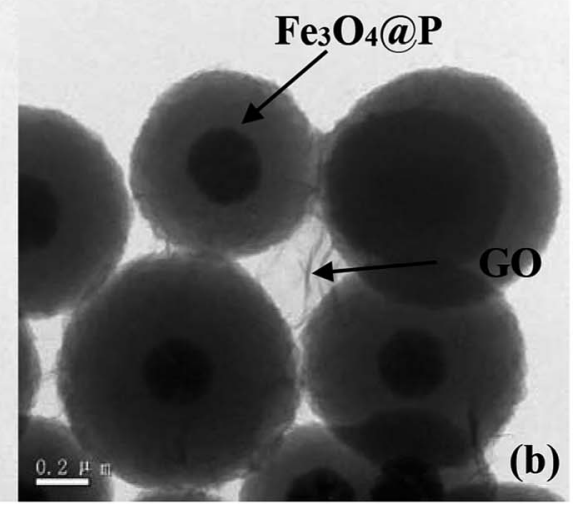

Fig. 1 TEM images of (a) $\mathrm{Fe}_{3} \mathrm{O}_{4} \mathrm{QP}$, and (b) $\mathrm{GO}-\mathrm{Fe}_{3} \mathrm{O}_{4} \mathrm{QP}$.

(2) Fig. 2(a) and the related discussion contained some errors in the original manuscript. The original FTIR characterization data was sent to a third party as the authors did not know how to convert the original data into the FTIR graphs. The authors admit that they did not carefully check the results and inadvertently supplied the FTIR data for a different material.

The corrected version of Fig. 2(a) and the corrected sentences are shown here:

Page 63496 (right column), paragraph 2: "As shown in Fig. 2(a), the characteristic peak of $\mathrm{Fe}_{3} \mathrm{O}_{4}$ occurs at $588 \mathrm{~cm}^{-1}$. Other typical peaks could be assigned as follows, $\nu\left(-\mathrm{OH},-\mathrm{NH}_{2}\right): 3440 \mathrm{~cm}^{-1} ; \nu\left(-\mathrm{CH}_{2},-\mathrm{CH}_{3}\right): 2949 \mathrm{~cm}^{-1}, 2843 \mathrm{~cm}^{-1} ; \nu(-\mathrm{C}=\mathrm{O}): 1726 \mathrm{~cm}^{-1}$; $\delta(-\mathrm{CONH}-): 1639 \mathrm{~cm}^{-1} ; \delta(\mathrm{N}-\mathrm{H}): 1570 \mathrm{~cm}^{-1} . "$

${ }^{a}$ College of Biology and Environmental Engineering, Zhejiang Shuren University, Hangzhou 310015, China

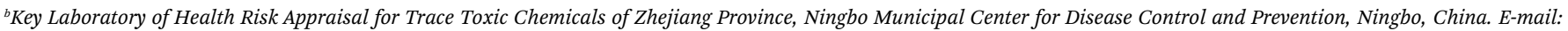
jmcjc@163.com

${ }^{c}$ Ningbo Key Laboratory of Poison Research and Control, Ningbo Municipal Center for Disease Control and Prevention, Ningbo, China 
Page 63498 (left column), paragraph 2: "Besides, the characteristic peak of N-H bond at $1570 \mathrm{~cm}^{-1} \mathrm{shifted} \mathrm{to} 1533 \mathrm{~cm}^{-1}$, indicating the formation of hydrogen bond between 2,4,6-TCP and $-\mathrm{NH}_{2}$ groups on $\mathrm{GO}_{-} \mathrm{Fe}_{3} \mathrm{O}_{4} @ \mathrm{P}$. ${ }^{23}$ It was worth noting that the peaks at $1452 \mathrm{~cm}^{-1}$ and $1392 \mathrm{~cm}^{-1}$, due to the skeletal vibration of aromatic $\mathrm{C}=\mathrm{C}$ bonds, shifted to $1431 \mathrm{~cm}{ }^{-1}$ and $1362 \mathrm{~cm}^{-1}$, respectively, confirming the $\pi-\pi$ stacking interactions were formed between the benzene ring of 2,4,6-TCP and the hexagonal skeleton of the GO sheet of GO-Fe $\mathrm{O}_{4} @ \mathrm{P}^{24}$ "

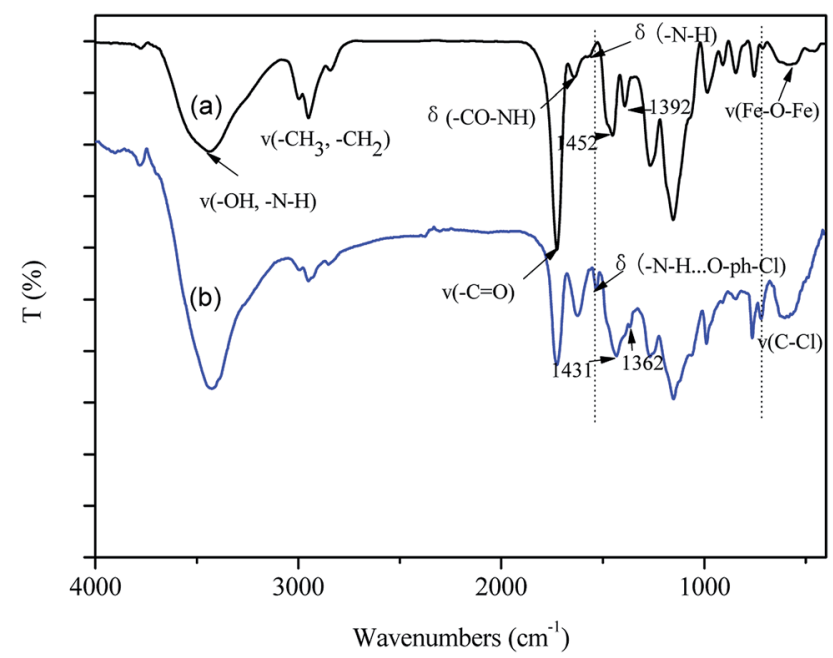

Fig. 2 FTIR curves of (a) GO- $\mathrm{Fe}_{3} \mathrm{O}_{4} \mathrm{aP}$ and (b) GO- $\mathrm{Fe}_{3} \mathrm{O}_{4} \mathrm{aP}-\mathrm{TCP}$.

(3) Fig. 5(b, c) and the related discussion contained some errors in the original manuscript. The original fluorescence spectroscopy (FL) characterization data was sent to a third party as the authors needed help to convert the original FL data into curves. The authors believe that they have confused the original data and made some mistakes during the process of data transfer. The authors admit that they did not carefully compare the FL curves with the original data.

The corrected version of Fig. 5(b, c) and the corrected sentences are shown here.

Page 63498 (left column) paragraph 2: "The N 1s high-resolution scan of GO- $\mathrm{Fe}_{3} \mathrm{O}_{4} @ \mathrm{P}$ could be deconvoluted into two individual peaks at binding energies of $400.7 \mathrm{eV}$ and $399.3 \mathrm{eV}$, which could be assigned to $\mathrm{N}-\mathrm{H}$, and C-N, respectively. After 2,4,6-TCP adsorption, the binding energy of $\mathrm{N}-\mathrm{H}$ bond shifted to $400.4 \mathrm{eV}$, which may be due to the formation of hydrogen bond between 2,4,6-TCP and the amine groups on the surface of GO- $\mathrm{Fe}_{3} \mathrm{O}_{4} @ \mathrm{P} . "$

Page 63498 (left column) paragraph 2: "The results indicated that the fluorescence intensities at $\sim 309 \mathrm{~nm}$ of GO-Fe $\mathrm{O}_{4} @ \mathrm{P}$ were quenched a lot after 2,4,6-TCP adsorption, implying the $\pi-\pi$ stacking interaction appeared between 2,4,6-TCP and GO-Fe ${ }_{3} \mathrm{O}_{4} @ \mathrm{P}$."
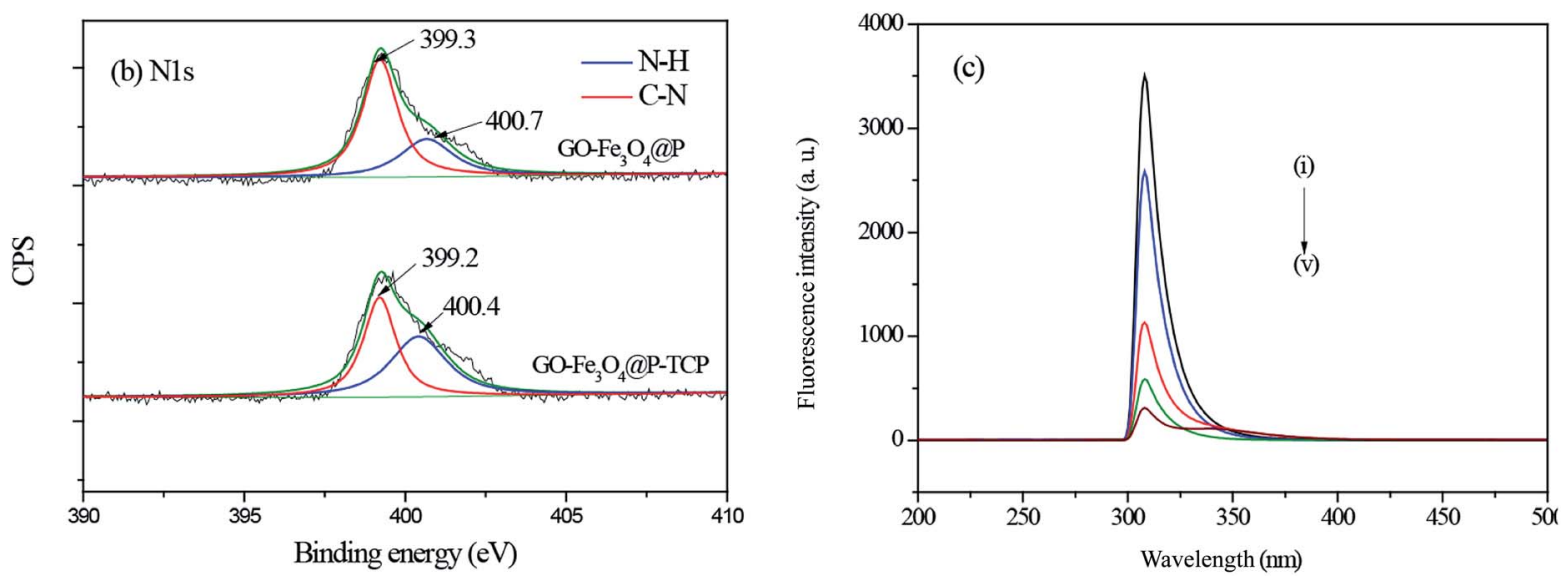

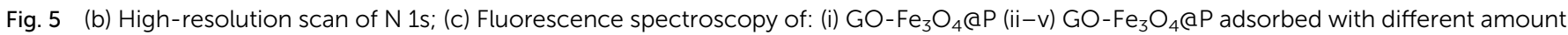
of 2,4,6-TCP (initial 2,4,6-TCP concentrations at $10 \mathrm{mg} \mathrm{L}^{-1}, 100 \mathrm{mg} \mathrm{L}^{-1}, 200 \mathrm{mg} \mathrm{L}^{-1}$, and $500 \mathrm{mg} \mathrm{L}^{-1}$, respectively).

The Royal Society of Chemistry apologises for these errors and any consequent inconvenience to authors and readers. 